RESEARCH PAPER

\title{
Online sales: profit without question
}

\section{J A Bryant, M J Cody, S T Murphy}

See end of article for

authors' affiliations

Tobacco Control 2002;11:226-227

......................

Correspondence to: Michael J Cody, School of Communication,

Annenberg School for

Communication, University of Southern California,

3502 Watt Way, Office

326, Los Angeles, CA

90089-0281, USA;

cody@rcf.usc.edu

Received 23 October 2001 and revision requested 4 April 2002

Accepted 7 June 2002
Objectives: To examine the ease with which underage smokers can purchase cigarettes online using money orders and to evaluate the effectiveness of internet filtering programs in blocking access to internet cigarette vendors (ICVs).

Design: Four young people purchased 32 money orders using 32 different names to buy one carton of cigarettes for each named individual. Each money order was subsequently mailed to a different ICV in the USA. No age related information accompanied these online orders. Two internet filtering programs ("Bess" and filtertobacco.org) were tested for their relative efficacy in blocking access to ICV sites.

Results: Of the 32 orders placed, four orders never reached the intended ICV. Of the remaining 28 orders, $20(71 \%)$ were filled despite a lack of age verification. Only four $(14 \%)$ of the orders received were rejected because they lacked proof of age. "Bess" blocked access to $84 \%$ and filtertobacco.org to $94 \%$ of the ICV sites.

Conclusions: Although underage smokers can easily purchase cigarettes online using money orders, access to these sites can be largely blocked if appropriate filtering devices are installed. n 1998, the Master Settlement Agreement established certain restrictions on the advertising and promotion of tobacco products. However, the final version of the agreement did not include the world wide web, ${ }^{1}$ and the tobacco industry is thriving in this unregulated online environment. In February 2000 there were approximately 40 websites selling cigarettes. ${ }^{2}$ By November of that same year, there were 68 sites-an increase of $70 \%$ in a 10 month timespan. ${ }^{3}$ Hong and Cody $y^{4}$ randomly sampled a large sample of websites related to tobacco and found that half of all tobacco related sites (159 sites of 318) were portals to cheap and usually tax-free cigarettes.

Recent attempts at monitoring online tobacco sales to minors have shown that underage smokers have relatively easy access to tobacco via the internet. A series of studies, including several "sting operations", indicate that cigarettes continue to be sold over the internet to anyone with a credit card, without proof of age. ${ }^{25-7}$ Despite the negative publicity surrounding such sting operations ${ }^{8}$ and fines of $\$ 25000$ for each online sale to an underaged person, ${ }^{5}$ the internet continues to provide ready access to cheap, untaxed cigarettes without requiring proof of age.

Some internet tobacco vendors have argued that the use of a credit card acts as a barrier to underage smokers purchasing tobacco online, in effect shifting the responsibility for providing a minor with cigarettes from the online vendor to the adult credit card holder. But not all online tobacco orders are placed using credit cards. Many internet cigarette vendors (ICVs) provide an option for payment by money orders. In fact, a recent content analysis of ICVs found that $68 \%$ of the sites allowed payment by money order or certified cheque. ${ }^{3}$ Of those sites that allowed money orders only $81 \%$ specified age restrictions. Moreover, of those sites with age warnings, 52\% verified a customer's age only by self report, 15\% by typing in a date of birth, $7 \%$ by entering driver's licence information, and $8 \%$ by some other method. ${ }^{3}$ Unlike credit cards that carry with them the assumption that the purchaser is of legal age (a point frequently made by ICVs), money orders can be easily obtained by any individual with cash on hand regardless of age.

The primary goal of the present study was to test the ease with which underaged smokers could purchase cigarettes online using money orders. The secondary goal was to investigate whether existing internet filtering programs can successfully block access to ICVs. Consequently, the present study will also include a comparison of "Bess", currently the most effective blocking program, ${ }^{9}$ and the filtertobacco.org ${ }^{10}$ filtering program.

\section{DESIGN}

The first phase of this study focused on investigating whether an individual can purchase a carton of cigarettes from an ICV using money orders without proving that they are 18 years or older. Thirty two ICVs who accept money orders were identified by entering the terms "cigarette" and "money order" into a Google search to locate those cigarette vendors with the highest hit rate, and then cross checking those vendors with a list of 159 sites created from earlier research. ${ }^{4}$

All but one site contained a statement that a person had to be of legal age ( 18 years and older) to buy cigarettes, but the location and type of statement varied significantly from site to site. Only seven $(22 \%)$ claimed on the order form that proof of age via driver's licence or other government issued documentation was required. Another nine sites (28\%) had buyers sign a statement claiming that they are 18 years of age or older.

We then recruited four smokers who agreed to loan their last name and address so that the cigarettes could be sent to an actual residence. Eight variations of each person's name were created by altering their first name to order to suggest the individual male in four of the identities and female in the other four (Edwin, Edwina, Ed, Edna, etc.).

Finally, an order form was either completed and submitted online (with payment to be mailed before shipping), or printed, completed, and mailed in with the payment. For ethical and legal reasons we could not actually use "underaged" volunteers to buy the money order and buy the cartons; therefore, four youthful looking college students, who are frequently mistaken for minors and "carded", purchased the money orders at various locations. These individuals were never asked for proof of age when purchasing the blank money orders (the name of the recipient was completed later). The money orders were then sent with the appropriate shipping information to the 32 ICVs without any proof of age 
(even if the order form stated that a copy of one's driver's licence was required).

The second phase of the study involved assessing whether or not internet filtering programs can successfully block access to online retail tobacco sites. After cartons were ordered and sufficient time had passed for cartons to arrive, the "Bess" $\mathrm{N} 2 \mathrm{H} 2$ program was installed and each of the 32 sites were visited in order to see if the program successfully blocked access to the sites, first set at "maximum filtering", and then set at "standard school filtering". The "Bess" program was then uninstalled and each of the 32 web sites was entered into the "test a site" feature at filtertobacco.org to see whether it was on the "blocked" list.

\section{RESULTS}

\section{Buying online}

Of the 32 orders placed, three money orders were returned unopened by the US postal service with a note informing the sender that the ICV vendor was no longer operating at the address noted on their website (these addresses were checked and the orders resubmitted to no avail). One other order was returned for insufficient postage. These four orders, then, never reached their intended ICV.

Of the remaining 28 orders received by an ICV, 20 (approximately $71 \%$ ) were received and filled. Only 4 (14\%) of the 28 orders received by the ICVs were rejected because of a lack of proof of age (one due to both a lack of proof of age and problem with the order). The remaining four unfilled orders were rejected for a variety of reasons not listed on the web site (for example, one ICV said it did not ship to California, another said it required a "minimum" order of more than one carton).

\section{Filtering tobacco web sites}

The "Bess" N2H2 program resulted in identical outcomes for both "maximum" and "standard school" filtering, and blocked $84 \%$, or all but four sites out of 31 web sites (one site, expresssmokes.com, was under construction and appeared to be changing from a tobacco sales site to some type of patriotic web site). All but two of the web sites were found to be on the "not list" by filtertobacco.org. Thus, access to $94 \%$ of the 32 sites was blocked using this program.

\section{DISCUSSION}

The present study confirms the relative ease with which underage smokers can purchase cigarettes online using money orders. Of the 28 online tobacco websites who received money orders $71 \%$ sent cartons of cigarettes to customers without age verification. Of the eight ICVs who received a money order but did not fill the order, only $14 \%$ cited lack of age verification as the reason for the refusal. Our study also revealed an important inconsistency within several ICV websites which claimed to enforce age verification stringently, but subsequently filled orders with no such verification. Our results indicate that this public statement does not guarantee that individuals processing the orders will actually bother with monitoring the proof when the order arrives.

According to the Centers for Disease Control and Prevention, in the past decade smoking among high school students has increased $50 \%$ in half of the states it has surveyed. ${ }^{11}$ In 1998 and 1999, 45.2\% of middle school students had tried

\section{What this paper adds}

Cigarettes are readily available online to anyone with a credit card. Money orders can also be used to purchase cigarettes online without proof of age. Access to online vendors can be effectively blocked using filtering programs such as "Bess" and filtertobacco.org

cigarettes and $15 \%$ were already considered regular smokers. ${ }^{7}$ By high school $71.9 \%$ of students had tried cigarettes and $32.7 \%$ were regular smokers. Our research suggests that by allowing underage smokers the opportunity to purchase cigarettes online easily using money orders, the internet may be an important conduit in this process. On a more positive note, our results also show that filtering programs like "Bess" N2H2 and filtertobacco.org offer a way to make the internet relatively tobacco-free by blocking access to online cigarette vendors the vast majority of the time.

\section{ACKNOWLEDGEMENTS}

This research was made possible with funding from Proposition 99 to University of Southern California Contract $99-85316$ by CDHS/TCS. The following individuals provided invaluable help in conducting the research reported in this paper: Ishita Sinha Roy, Bud Perkins, Ken Gillispie, Tamara Clark, Stacey Weiland, Jessica Moore, and Zack DuRant.

\section{Authors' affiliations}

J A Bryant, M J Cody, S T Murphy, School of Communication, Annenberg School for Communication, University of Southern California, Los Angeles, California, USA

\section{REFERENCES}

1 National Association of Attorneys General. Master Settlement Agreement. 1998. Access date: April 2001. URL: http:// www.naag.organization.

2 Noack D. Utah recruits kids to buy smokes online. Proposed laws would plug loopholes. Salt Lake City. February 2000. Access date: April 2001 URL: http://www.APBnews.com.

3 RibisI KM, Kim AE, Williams RS. Are the sales practices of Internet cigarette vendors good enough to prevent sales to minors? Am J Public Health (in press).

4 Hong T, Cody M. Presence of pro-tobacco messages on the web. Journal of Health Communication (in press).

5 Stone $\mathbf{M}$. Oregon stings four web tobacco dealers for minor sales. NewsFactor Network. February 2000. Access date: April 2001. URL: http://wireless.newsfactor.com/perl/printer/2457/

6 Enos L. Tobacco E-tailer sued for sales to minors. NewsFactor Network. 28 December 2000. Access date: April 2001. URL: http:// wireless.newsfactor.com/perl/printer/6345/.

7 Radziejewski J, Ortiz K. Department of Consumer Affairs cracks down on mail-order \& internet tobacco dealers who sell cigarettes to minors. 12 April 2001. Access date: April 2001. URL: http://www.ci.nyc.ny.us/ $\mathrm{html} / \mathrm{dcs} / \mathrm{html} /$ cigsminors. html.

8 Getting Smokes Online. Children buying cigarettes with click of mouse. Good Morning America. March 2001. Access date: April 2001. URL: http://www.ABCNews.com.

9 Reagan K, Hong T, Cohen E, et al. Blocking access to online tobacco sales sites. Tobacco Control 2002;11:164-5.

10 Filtertobacco.org. Filtertobacco.org is available online, and is offered by scholars working at Yale University. Access date: 1 June 2002. URL: hitp://www. filtertobacco.org/

11 Center for Disease Control and Prevention. Youth tobacco surveillance United States, 1998-1999. Atlanta, Georgia. October 2000. Access date: April 2001. URL: http://www.cdc.gov/tobacco/ research_data/youth/ss4910.pdf 